\title{
A imprensa brasileira, o golpe civil-militar de 1964 e a Comissão Nacional da Verdade
}

\section{Carmen Regina Abreu Gonçalves}

Universidade Federal do Pampa, Programa de Pós-Graduação em Comunicação e Indústria Criativa, São Borja, RS, Brasil

ORCID: https://orcid.org/0000-0001-8170-6950

\section{Elisa Lübeck}

Universidade Federal do Pampa, São Borja, RS, Brasil ORCID: https://orcid.org/0000-0002-9176-0050

\section{Resumo}

Neste texto, discutimos a participação da imprensa na deposição do presidente João Goulart, golpe de 1964, e a cobertura sobre o trabalho da Comissão Nacional da Verdade realizada pelos jornais Folha de São Paulo, O Estado de São Paulo e O Globo. Nosso objetivo foi destacar os principais sentidos que circularam, se destacaram, foram silenciados e/ou apagados sobre a ditadura civil-militar brasileira e a Comissão Nacional da Verdade no discurso dos jornais. Nesta cobertura, a CNV é desqualificada, deslegitimada e são colocados sob suspeição sua finalidade, objetivos e resultados. Acreditamos que o cenário histórico, político, social, cultural e econômico que o Brasil enfrenta tem origem, principalmente, em seu passado mal resolvido.

\section{Palavras-chave}

Comissão Nacional da Verdade; Ditadura civil-militar; Golpe de 1964; Jornalismo

\section{Introdução}

É preciso falar sobre o passado mal resolvido do Brasil. A ditadura civil-militar brasileira perseguiu, prendeu, torturou, matou. São muitas vítimas. Uma delas foi o diretor de jornalismo da TV Cultura, Vladimir Herzog, o Vlado. Torturado e morto na sede do Destacamento de Operações de Informação - Centro de Operações de Defesa Interna (DOICodi), em São Paulo. 0 assassinato ocorreu no dia 25 de outubro de 1975. Os crimes cometidos pela ditadura brasileira são crimes contra a humanidade e imprescritíveis.

Em 2021, o golpe civil-militar de 1964 completou 57 anos. Um macro acontecimento 
que se destaca na história política brasileira pelas marcas que imprime em trajetórias de vidas, individuais e coletivas, correspondendo a experiências memoráveis, a rupturas e inícios (QUÉRÉ, 2005). 0 golpe de 1964 dá origem a vários outros acontecimentos da história recente do Brasil. Um destes acontecimentos, decorrentes da ação dos militares e de seus apoiadores, ocorreu quase três décadas depois do fim da ditadura civil-militar, a criação da Comissão Nacional da Verdade (CNV). Um acontecimento social, político, histórico que correspondeu aos requisitos para ingressar no circuito midiático como acontecimento jornalístico.

A CNV nasceu em meio a uma disputa histórica, que permanece, ainda hoje, sobre o que foi a ditadura civil-militar brasileira, e inseriu-se em um circuito comunicacional que incluiu, entre outros, os meios de comunicação, o campo jurídico, o governo federal, o congresso nacional, os que trabalharam para sua criação e os que envidaram esforços para que não fosse realizada. Nesse jogo comunicacional, existe uma relação de forças, uma disputa pela "palavra final" sobre a verdade histórica e a memória oficial que a sociedade brasileira deve ter do período ditatorial.

Uma disputa que continua e está fortalecida com a atual presidência do Brasil. Já que em março de 2019, o Governo Federal instruiu as Forças Armadas a fazer atos alusivos aos 55 anos do golpe (FERREIRA; URIBE, 2019). Em fevereiro de 2019, 46 militares já ocupavam posições estratégicas no Governo Federal (TREZZI, 2019). Dos 23 ministérios, nove têm ministros com origem nas Forças Armadas, sendo o vice-presidente do Brasil um general da reserva. Um cenário preocupante para um país que ainda não tem seu processo democrático consolidado.

A Comissão Nacional da Verdade foi criada em 2011 e 31 meses depois encerrou seu trabalho. Era o ano do cinquentenário do golpe, 2014. A CNV foi criada com a finalidade de examinar e tentar esclarecer as graves violações de direitos humanos que ocorreram no país, entre 1946 e 1988, a fim de efetivar o direito à memória, à verdade histórica e promover a reconciliação nacional. Já nasceu polêmica.

A criação da CNV foi um marco, um acontecimento simbólico e disputado, acima de tudo, pelo poder de revelação que detinha, por ocorrer em um presente em transformação e situar-se entre o passado e o futuro da história do Brasil. Enfrentou diversos obstáculos e limitações para realizar seu trabalho, dentre eles pressões, questões políticas e de ordem organizacional, como o número reduzido de integrantes. Até que a criação da CNV fosse efetivada, uma longa e difícil negociação foi realizada entre instâncias de poder. Muitas 
concessões foram feitas por parte do governo federal para que ela existisse (ABREU, 2016).

Desde o começo, o grupo sofreu críticas e enfrentou resistências por parte daqueles que não queriam ver o passado do País revisitado. Organizada pelo campo político, a Comissão teve entre seus principais desafios romper o silêncio, revelar acontecimentos, fatos e versões que muitos não queriam/querem que apareçam e ainda precisava atender às expectativas de ex-presos políticos, familiares de mortos e desaparecidos e dos movimentos que lutam por justiça e direitos humanos.

O campo do jornalismo tem e teve um papel fundamental neste processo contínuo que pode ser considerado como um "acerto de contas" do Brasil com seu passado. Mais de 80 milhões de brasileiros nasceram sob o regime democrático e cerca de $80 \%$ da população brasileira nasceu depois do golpe civil-militar (COMISSÃO NACIONAL DA VERDADE, 2014a).

Continua sendo função do jornalismo contribuir para o esclarecimento do que aconteceu no país durante os 21 anos de ditadura militar. Os meios de comunicação é que elegem e determinam o que é importante para a sociedade, pois tematizam, agendam, escolhem as fontes, silenciam ou apagam.

O Brasil passou por uma transição para o regime democrático controlada pelos militares, que definiram sua forma e seus prazos. A cultura da impunidade e da violência nas forças de segurança do país, herdada da ditadura militar é muito expressiva. E, pode ser constatada diariamente, nos noticiários.

O Brasil foi o último dos países latino-americanos, que passaram por regimes ditatoriais, a criar uma comissão da verdade e isso diz muito sobre o processo que envolve a justiça de transição no país. Dentre as finalidades da justiça de transição, apontadas por Sabadell e Dimoulis (2011, p. 81) estão, “[...] discutir publicamente acerca da versão oficial dos fatos ocorridos durante o regime anterior (ou durante a situação de conflito interno ou externo) e da tomada de medidas políticas para evitar que se repita tal experiência: 'nunca mais!'.".

Falta ao Brasil fazer o enfrentamento sério e responsável das questões principais que compõem a justiça transicional. Ou seja, uma transição amparada nos princípios da verdade, memória, justiça, reparação e reforma das instituições não foi realizada na totalidade.

Para o professor Márcio Orlando Seligmann-Silva (2015), no Brasil

“A tradição de 'memoricídio', de assassinato da memória de nossa violência social, sempre aconteceu. O Brasil é um país extremamente violento, extremamente racista, onde justamente não existem espaços de locais de 
memória para se lembrar do genocídio dos africanos que vieram para cá, dos indígenas, que foram e ainda são dizimados.".

A memória é uma construção e, como tal, é perpassada, veladamente, por mediações que expressam relações de poder que hierarquizam, segundo os interesses dominantes, aspectos de classe, políticos e culturais. Deste modo, longe de ser um produto do acaso, a memória é resultado da relação e interação entre os diversos atores históricos em um determinado contexto (PADRÓS, 2001). A disputa pela memória é ideológica e política, diz Pollak (1992), assim, o que a memória individual grava, recalca, suprime, recorda, é evidentemente o resultado de um verdadeiro trabalho de organização e de seleção.

Continuamos vivendo, no Brasil, uma intensa e tensa disputa de versões sobre o que de fato foram os 21 anos de ditadura militar no Brasil. Essa disputa pela verdade histórica e pela memória, que também é de poder, é protagonizada pelos militares que insistem no silêncio sobre os crimes e as atrocidades que cometeram.

Um dos momentos em que essa disputa foi retomada, e evidenciada pelo jornalismo, ocorreu com a criação da Comissão Nacional da Verdade, um acontecimento histórico, social e jornalístico impregnado de passado e que ao mesmo tempo carregou uma expectativa de futuro. 0 jornalismo é um lugar de circulação e produção de sentidos (BENETTI, 2007). Sabese que o campo do jornalismo é permeado por relações de poder cujo principal produto, a notícia, é construída sob a influência de diversos fatores, entre eles os econômicos, ideológicos e os culturais, bem como a perspectiva do jornalista.

Neste texto, abordamos a participação da imprensa no golpe de 1964 e trazemos alguns pontos do que foi discutido em Abreu (2016), a partir da análise realizada em textos publicados nos jornais Folha de S.Paulo (FSP), O Estado de S.Paulo (OESP) e O Globo (Globo), que tratavam da instalação, do relatório final e de outros momentos de maior visibilidade da Comissão Nacional da Verdade.

O objetivo, aqui, é destacar os principais sentidos que foram produzidos e silenciados pelo discurso jornalístico sobre o acontecimento Comissão Nacional da Verdade e a ditadura militar brasileira, passados mais de 56 anos do golpe de 1964.

Segundo Orlandi (2007), quando se discute o silêncio, não se tem marcas formais, mas pistas, traços. É através de frestas, rupturas, falhas, que ele se mostra fugazmente. Segundo a autora, a política do silêncio (o silenciamento) expõe que - como o sentido é sempre produzido de um lugar, a partir de uma posição do sujeito -, ao dizer, ele estará, 
fundamentalmente, não dizendo "outros" sentidos. Isso produz um recorte necessário no sentido. "Dizer e silenciar andam juntos.", diz Orlandi (2007, p. 53). De acordo com Benetti (2007), o discurso jornalístico é, por definição, plural. Assim, o que se espera é que o texto jornalístico expresse, ao menos em parte, a pluralidade de visões sobre um determinado tema, porém nem sempre é o que acontece.

\section{A ditadura no Brasil: breve relato}

Só conhecendo o passado é possível compreender o presente e, assim, projetar o futuro. Foram 21 anos sob o comando dos militares que, com o apoio de diversos segmentos da sociedade brasileira, tiraram João Belchior Marques Goulart (Jango) da Presidência da República. Para Arendt (2011, p. 289) “[...] nem mesmo o mais autocrático tirano ou governante pode alçar-se algum dia ao poder, e muito menos conservá-lo, sem o apoio daqueles que têm modo de pensar análogo.".

No dia 13 de março de 1964, 19 dias antes do golpe, no comício na Central do Brasil, no Rio de Janeiro, figura 1, considerado simbólico e determinante para sua queda, Jango discursou para cerca de 150 mil pessoas, defendendo as reformas de base ${ }^{1}$.

Hoje, com o alto testemunho da Nação e com a solidariedade do povo, reunido na praça que só ao povo pertence, o governo, que é também o povo e que também só ao povo pertence, reafirma os seus propósitos inabaláveis de lutar com todas as suas forças pela reforma da sociedade brasileira." -discurso de João Goulart de 1964 (COMÍCIO CENTRAL DO BRASIL, 1964).

Figura 1 - Jango e a primeira-dama, Maria Thereza, no comício da Central do Brasil

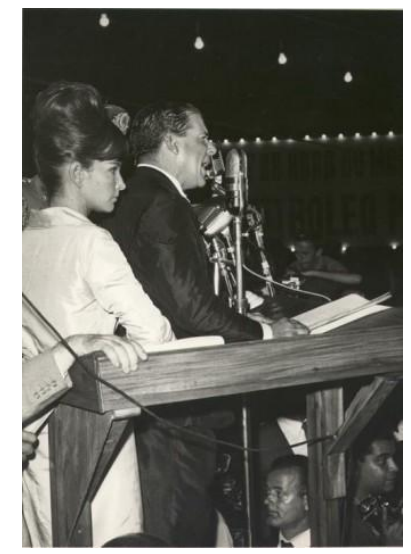

Fonte: Correio Braziliense (2019).

${ }^{1}$ Nessa ampla denominação de reformas de base, incluíam-se as reformas bancária, fiscal, urbana, eleitoral, agrária e educacional. 
Para a historiadora Maria Aparecida de Aquino (2015), existem muitas razões que levaram ao golpe de 64, mas as reformas de base seriam o elemento detonador dessa questão. "Essas reformas atingiriam todos os setores: penetrariam na educação, no mundo agrícola, na indústria. Era uma proposta para mudar o Brasil.", afirma Aquino (2015).

No dia 31 de março de 1964, o presidente João Goulart estava no Palácio das Laranjeiras, no estado da Guanabara, quando de Juiz de Fora, Minas Gerais, o comandante da 4⿳亠口冋 Região Militar, Olímpio Mourão Filho, marchava para pôr fim ao seu governo. De acordo com Ferreira (2011, p. 469), “Ao ler os jornais Jango se assustou: o editorial do Jornal do Brasil lhe desferia duras críticas. 0 texto sem rodeios pregava sua deposição. No Correio da Manhã, o título era 'Basta!'.”.

O documentário $O$ dia que durou 21 anos (2012), com direção de Camilo Tavares filho de uma das vítimas da ditadura, o jornalista Flávio Tavares -, apresenta documentos e gravações de diálogos da Casa Branca, de 1962 a 1964, que comprovam a participação do governo dos Estados Unidos na conspiração para derrubar Jango e também no golpe de 1964. A produção traz também detalhes de um plano de contingência que previa as etapas do golpe. Dentre elas, um Estado deveria se declarar contra o governo de Jango, como fez Minas Gerais, e os EUA deveriam reconhecer um presidente constitucional antes de um militar, como ocorreu com Mazzilli.

Diante da situação e sentindo-se ameaçado, Jango decide sair do Rio de Janeiro e ir para Brasília. De lá, foi para Porto Alegre com o objetivo de encontrar aliados políticos, como Leonel Brizola, e avaliar como e se poderia resistir ao movimento golpista. Enquanto Jango voava para a capital do Rio Grande do Sul, o Congresso Nacional oficializava a sua deposição. Depois de constatar que não tinha força militar para resistir aos golpistas, Jango teria dito, segundo versão de Brizola: “Eu verifico o seguinte. Que a minha permanência no governo terá que ser à custa de derramamento de sangue. E eu não quero que o povo brasileiro pague este tributo. Então eu me retiro.". (FERREIRA; GOMES, 2014, p. 368).

Jango foi para São Borja, sua terra natal, e no dia 4 de abril viajou para Montevidéu, no Uruguai. Com o golpe, o ex-presidente deixou Brasília para só voltar à capital do país 49 anos depois, em uma urna funerária. Jango morreu no dia 6 de dezembro de 1976, em sua fazenda em Mercedes, na Argentina. Foi o único presidente brasileiro a morrer no exílio. 


\section{A participação da imprensa no golpe de 1964}

A imprensa ${ }^{2}$ brasileira desempenhou um papel relevante no processo que conduziu o Brasil para um regime de exceção. Para Dantas (2014, p. 65), “A participação da mídia contribuiu de maneira decisiva para a implantação da ditadura que dominaria o país por 21 anos. Pode-se afirmar, sem temor de erro, que um único jornal, Última Hora, não aderiu ao golpe.". Ele destaca que os jornais O Estado de S.Paulo e O Globo participavam ativamente da conspiração para derrubar Jango. Aquino (2015) reforça essa teoria e diz que a imprensa teve um papel de protagonismo no golpe. "Eles foram conspiradores. Toda a grande imprensa estava na conspiração contra a democracia. Vai ser uma das articuladoras mais importantes do golpe." (AQUINO, 2015)

Na mesma direção, Ferreira (2011, p. 508) argumenta que existia uma ampla coalizão civil-militar. "A imprensa e os meios de comunicação não apenas apoiavam, mas incentivavam o golpe. Não se tratava só do apoio de empresários e latifundiários, mas de amplas parcelas das classes médias.".

Conforme Magalhães (2014), que reuniu 19 primeiras páginas de jornais e capas de revistas publicadas no início de abril de 1964, oriundos de cinco Estados brasileiros, apenas três se pronunciaram em defesa da Constituição: "Última Hora", "A Noite" e "Diário Carioca". Os dois últimos não tinham muitos leitores. De acordo o jornalista Juremir Machado da Silva (2014), João Goulart "enfrentou a ira moralista de veículos como o Correio da Manhã, Jornal do Brasil, O Globo, O Estado de S.Paulo, Folha de S.Paulo, Tribuna da Imprensa, O Dia e dos Diários Associados de Assis Chateaubriand". Silva (2017) defende a tese de que o golpe de 64 foi midiático-civil-militar, pois foi legitimado pela mídia.

Os jornais apoiaram a marcha da família. Motivada, principalmente, por uma fala de Jango no comício da Central ${ }^{3}$, em 19 de março, dia de São José, protetor da família, realizouse, em São Paulo, a "Marcha da Família com Deus pela Liberdade", reunindo cerca de 500 mil pessoas que gritavam palavras de ordem como "está chegando a hora de Jango ir embora",

\footnotetext{
2 Trecho do editorial do jornal 0 Globo, publicado na capa da edição de 02 de abril de 1964: "Vive a Nação dias gloriosos. Porque souberam unir-se todos os patriotas, independentemente de vinculações políticas, simpatias ou opinião sobre problemas isolados, para salvar o que é essencial: a democracia, a lei e a ordem [...] Este não foi um movimento partidário. Dele participaram todos os setores conscientes da vida política brasileira, pois a ninguém escapava o significado das manobras presidenciais. Aliaram-se os mais ilustres líderes políticos, os mais respeitados Governadores, com o mesmo intuito redentor que animou as Forças Armadas. Era a sorte da democracia no Brasil que estava em jogo." (RELEMBRE..., 2013).

${ }^{3}$ Para a historiadora Aline Pressot (2014), "Existem algumas versões a respeito da idealização da primeira Marcha da Família, mas todas elas convergem ao delegar à irmã Ana de Lurdes (Lucília Batista Pereira, neta de Rui Barbosa) a criação de um Movimento de Desagravo ao Rosário, que deu origem às Marchas. O Deputado Cunha Bueno (PSD) teria se indignado com o discurso proferido por Goulart na Central do Brasil e, reunindo-se com a irmã, teria recebido a sugestão e partido naquela mesma noite para os preparativos da Marcha paulista."
} 
(FICO, 2014, p. 62). Organizada pela União Cívica Feminina, Campanha da Mulher pela Democracia, Campanha da Fraterna Amizade Urbana e Rural, entre outras entidades, a marcha recebeu apoio de muitos empresários. Mais de 40 entidades assinaram o manifesto de convocação publicado na capa do O Estado de S.Paulo (MARCHA..., 1964). Segundo Ferreira e Gomes (2014, p. 302), "Abrindo a marcha estavam os cavalarianos dos Dragões da Força Pública. A seguir, na primeira fila, o deputado udenista Herbert Levy, o senador Auro Moura de Andrade e o general Nelson de Melo.". Os jornais cobriram a manifestação destacando que o movimento defendia a democracia, a constituição e a liberdade.

\section{Comissão Nacional da Verdade}

Embora sejam diferentes em alguns aspectos, inclusive no nome, as comissões da verdade - são registradas mais de 40 no mundo - têm em comum o objetivo de não deixar que o esquecimento político e social afete o futuro de um Estado Democrático de Direito. Elas são temporárias, têm um período pré-determinado e geralmente encerram seu trabalho com um relatório final. Uma das principais características deste tipo de instrumento da justiça transicional é o enfoque nas vítimas de graves violações de direitos humanos.

Para Mezarobba (2010), dentre os objetivos de uma comissão da verdade pode-se destacar: descobrir, esclarecer e formalmente reconhecer abusos do passado; restaurar a dignidade e facilitar o direito das vítimas à verdade; contribuir para justiça e prestação de contas; acentuar a responsabilidade do Estado e recomendar reformas; promover a reconciliação, reduzir conflitos e estabelecer a legitimidade de um novo regime.

A criação da Comissão Nacional da Verdade, em 2012, 27 anos depois do fim da ditadura, foi considerada como um passo significativo em direção ao direito à memória e à verdade. A sua efetivação foi resultado de uma intensa e tensa discussão que envolveu, principalmente, o Governo Federal, as Forças Armadas e o Congresso Nacional.

Um dos momentos mais marcantes e um dos poucos que obteve visibilidade da imprensa ocorreu no final de abril de 2013, quase um ano após o início das atividades da CNV. A primeira convocação. Foi chamado a depor, no dia 10 de maio, em audiência pública (a primeira com essa característica), o coronel da reserva Carlos Alberto Brilhante Ustra, figura 2, ex-comandante do DOI-Codi de SP, entre 1970 e 1974 (auge da repressão violenta). Ustra foi homenageado, em 2016, pelo então deputado federal Jair Bolsonaro, durante votação do impeachment da ex-presidente Dilma Rousseff. 
Após ser convocado, Ustra solicitou um habeas corpus na Justiça Federal de Brasília, para não comparecer ao depoimento. 0 pedido foi negado pelo juiz, que deferiu somente o direito ao coronel de não responder às perguntas para não produzir prova contra si mesmo.

Figura 2 - Ustra durante depoimento à CNV

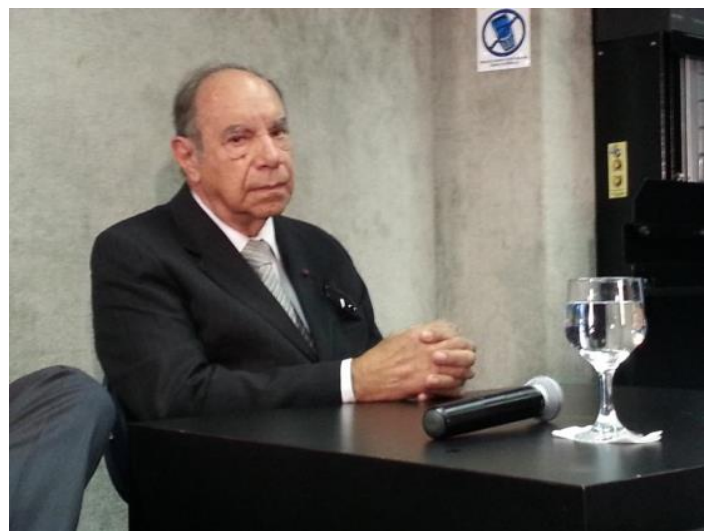

Fonte: Comissão Nacional da Verdade (2012)

O depoimento foi transmitido ao vivo pela CNV e obteve significativa repercussão nos meios de comunicação, conquistando espaço nas capas dos jornais, figuras 3 e 4 .

Figura 3 - Reprodução capa do OESP de 11/05/13

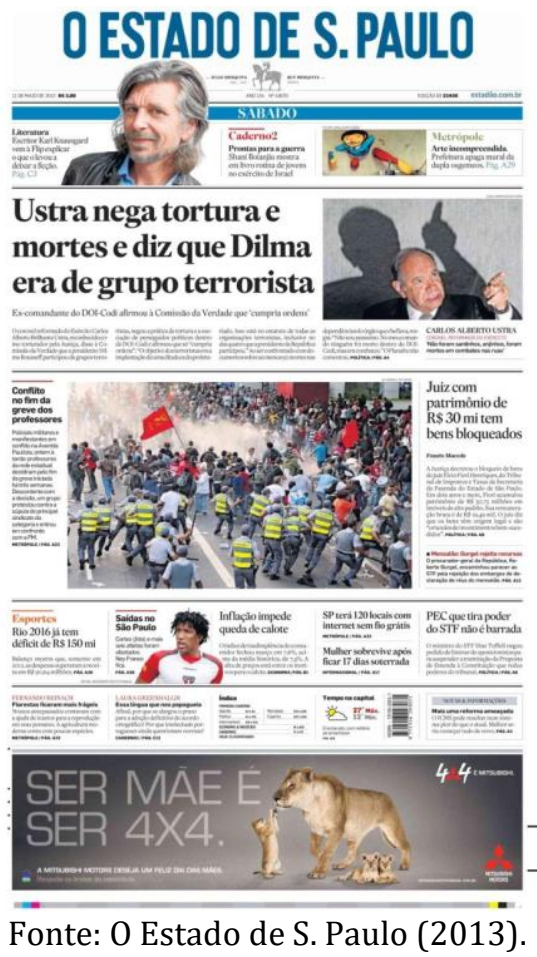


Figura 4 - Reprodução capa da FSP de 11/05/13

\section{FOLHA DE S.PAULO}

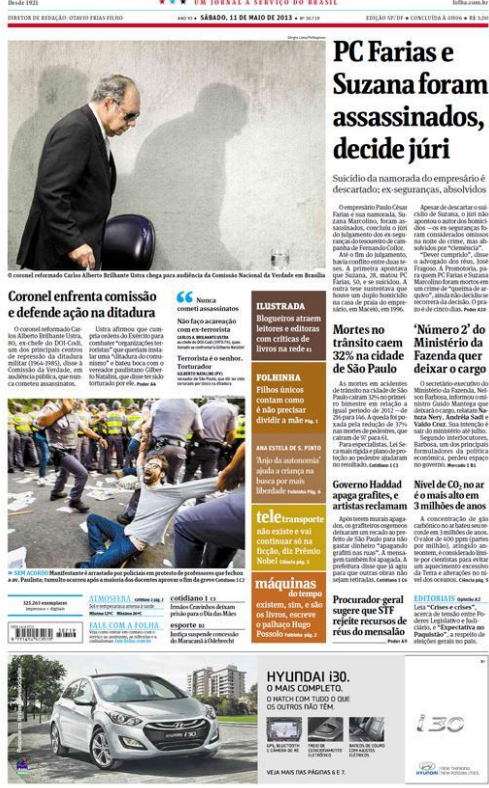

Fonte: Folha de S.Paulo (2013).

Em seu depoimento, quando por diversas vezes alterou a voz, se irritou e bateu na mesa, Ustra, conhecido pelo codinome de Major Tibiriçá durante a ditadura, contestou as acusações de tortura e de assassinatos cometidas enquanto foi comandante do DOI-Codi. Na sua versão, toda a ação do regime militar teve como objetivo proteger o país de uma "implantação do comunismo". "Nunca fui um assassino, graças a Deus nunca fui, quero deixar isso bem claro", afirmou Ustra (2013).

Para contrapor o coronel, os integrantes da CNV, Claudio Fonteles e Jose Carlos Dias, mostraram fotos de presos políticos mortos pelo DOI-Codi na repressão, caso de Frederico Eduardo Mayr, baleado e preso na avenida Paulista por uma equipe do DOI, onde, segundo testemunhas, foi torturado. 0 coronel olhou a foto e, depois de manifestar o desejo de não responder, voltou atrás e falou que Mayr morreu atropelado por um caminhão.

Antes do coronel, falou, na audiência, o ex-preso político e vereador de São Paulo Gilberto Natalini, que aos 19 anos foi torturado por Ustra. Ex-presidente da Comissão da Verdade da Câmara de Vereadores de São Paulo, ele contou que foi preso, em 1972, por uma equipe do DOI, onde foi torturado por mais de 60 dias, acusado de divulgar jornais "subversivos". Na prisão, ele escrevia poesias românticas e também algumas de protesto, e foi descoberto por Ustra. "Um dia ele me pegou, me despiu, me colocou em pé numa poça d'água, 
ligou fios no meu corpo e, pessoalmente, chamou a tropa, uma turma, para fazer uma sessão de declamação de poesia." (NATALINI, 2013). De acordo com Natalini (2013), “[...] ele queria que eu declamasse para a tropa dele as poesias que eu escrevia contra o regime e ficava me batendo com um cipó, durante horas e horas, ele mesmo, pessoalmente, me batendo.".

Fonteles (2013) apresentou ao coronel Ustra uma documentação confidencial que encontrou no Arquivo Nacional, elaborado, segundo o integrante da CNV, "pelo Serviço Nacional de Informações, portanto um documento produzido pela cadeia de informações da estrutura do estado ditatorial militar". Entre os documentos, um encaminhamento ao II Exército que apresenta um relatório periódico de estatística de informações secretas de outubro de 1973, sob o comando de Ustra, "mortos dentro do Doi-Codi do II Exército 50", disse Fonteles (2013). Mesmo depois de dizer que não responderia mais as perguntas da $\mathrm{CNV}$, o coronel rebateu dizendo que a documentação não era secreta, que tudo estava no seu livro (USTRA, 2006) e que as mortes não ocorreram dentro do DOI, e sim "em combate", gritou Ustra (2013).

Ustra morreu, aos 83 anos, no dia 15 de outubro de 2015. Ele se tornou, em 2008, o primeiro militar a ser reconhecido como torturador pela Justiça brasileira.

Os clubes militares tentaram impedir a divulgação do relatório final da CNV. Buscaram na justiça, por meio de uma série de pedidos, a suspensão da apresentação dos resultados. Na semana anterior à entrega, a justiça negou a última das solicitações dos militares que tinha como argumento o de que a "verdade histórica" poderia ser prejudicada pelo documento, pois o relatório não trataria dos crimes cometidos por militantes de esquerda. Para os militares, todos os "crimes" deveriam ser apurados. Foi neste complexo contexto que a Comissão Nacional da Verdade entregou seu relatório final, em 10 de dezembro de 2014.

O relatório com o total de 4.400 páginas é dividido em três volumes e está disponível para download (COMISSÃO NACIONAL DA VERDADE, 2014b). De acordo com o relatório da $\mathrm{CNV}$, as violações aos direitos humanos foram uma política de Estado, objetivando extinguir a oposição ao regime militar. 0 trabalho da Comissão mostra o período da ditadura militar associado a um quadro de violações massivas e sistemáticas de direitos humanos, em que os contrários ao regime, e todos aqueles que de alguma forma eram percebidos por este como seus opositores, foram perseguidos de diversas maneiras. São muitos os exemplos, entre eles, a cassação de mandatos eletivos e de cargos públicos, censura e outras restrições à liberdade de comunicação e expressão, punições relativas ao exercício da atividade profissional 
(transferências, perda de comissões, afastamento, demissões) e exclusão de instituições de ensino. Entre as questões fundamentais do relatório, está a comprovação oficial da tortura.

\section{Discurso jornalístico sobre a CNV}

Para essa reflexão, utilizamos pressupostos da Análise de Discurso (AD) nas análises dos textos. Aqui apresentamos um resumo de Abreu (2016), em que se discutiu a cobertura do trabalho da CNV nos jornais FSP, OESP e GLOBO. 0 universo de análise foi composto por todas as edições impressas (total de 60) dos três jornais, de 10 a 20 de maio de 2012 e de 7 a 15 de dezembro de 2014, períodos que incluem a divulgação dos nomes dos integrantes da CNV, a posse dos escolhidos por Dilma Rousseff, a instalação da Comissão e a entrega do relatório final.

A partir de um quadro de formações discursivas (FDs), pertencentes aos textos que integraram o corpus da pesquisa foi possível identificar algumas das principais marcas do discurso dos jornais FSP, OESP e GLOBO sobre a ditadura militar e a CNV. As sequências discursivas (SDs) que servem como ilustração para identificação das principais marcas pertencem aos textos que foram analisados. Essas SDs foram retiradas de textos informativos e de editoriais dos jornais, publicados nos dois períodos, já mencionados.

Sequências discursivas (grifos nossos):

a) “Na área militar, há grupos resistentes à própria criação da Comissão da Verdade, temendo 'revanchismo' e vendo no trabalho uma tática para rever a Lei da Anistia, aprovada em 1979.". (O ESTADO DE S. PAULO, 11/05/2012);

b) “Comissão da Verdade agirá 'doa a quem doer, diz Dipp.". (O ESTADO DE S. PAULO, 12/05/2012);

c) “A lei é clara [...] tampouco dá margem à revisão da Lei da Anistia, um dos pilares que asseguraram a transição da ditadura para o mais bem-sucedido regime democrático conhecido pelo país.". (FOLHA DE S.PAULO, 12/05/2012);

d) “Os agentes militares [...] seja lá o que tiverem feito durante os 'anos de chumbo', não poderão ser processados, devido à Lei de Anistia, promulgada em agosto de 1979 e endossada pelo Supremo Tribunal Federal, por 7 votos a 2, em abril de 2010.". (O ESTADO DE S.PAULO, 13/05/2012);

e) "Comissão deve focar violência dos dois lados, diz ex-ministro.". (FOLHA DE S.PAULO, 14/05/12);

f) "Comissão da Verdade já se divide sobre foco. A um dia de a Comissão da Verdade tomar posse, há discordância entre seus integrantes sobre a investigação: se deve 
focar violações supostamente cometidas só por agentes públicos ou também por militantes políticos. Para o diplomata Paulo Sérgio Pinheiro, o foco é o crime de agentes públicos: 'Não existe essa bobajada de dois lados. 0 outro lado já foi assassinado'.". (0 GLOBO, 15/05/2012);

g) “Não tem dois lados, o outro foi assassinado.". (O GLOBO, 15/05/2012);

h) "Membros da comissão da verdade querem apurar apenas ação de agentes do estado.". (O ESTADO DE S.PAULO, 15/05/2012);

i) “A revanche nunca teve respaldo jurídico, porque a Lei de Anistia, de 1979, aprovada ainda no governo militar de João Baptista Figueiredo, foi ampla, geral e recíproca. Quer dizer, beneficiou os dois lados.". (O GLOBO, 16/05/2012);

j) “Acordo prevê que esquerda será investigada, afirma Jobim.". (FOLHA DE S.PAULO, 16/05/2012);

k) 'Disse que a comissão não será movida por revanchismo, evitando 'confrontos inúteis', e que respeitará os 'pactos políticos' que nos levaram à redemocratização, em referência à Lei de Anistia.". (O ESTADO DE S.PAULO, 17/05/2012);

l) "Militares dizem que versões contêm meia verdade.". (O GLOBO, 18/05/2012);

m) “A reconstituição das circunstâncias em que ocorreram, com a identificação dos responsáveis por torturas, mortes e ocultação das vítimas, não têm por objetivo derrogar a Lei da Anistia, de 1979, punindo os culpados pelas abominações cometidas.". (O ESTADO DE S. PAULO, 18/05/2012);

n) "Comissão da Verdade é 'moeda falsa', diz general.". (O ESTADO DE S.PAULO, 18/05/2012);

o) "Grupo fracassa na tentativa de encontrar mortos e desaparecidos.". (FOLHA DE S.PAULO, 07/12/2014);

p) "Lei da Anistia dividiu a comissão desde a sua implantação.". (O ESTADO DE S.PAULO, 08/12/2014);

q) "O texto inclui, entre os citados por abusos, cinco generais que presidiram o Brasil. Para a comissão, a Lei da Anistia - aprovada em 1979, incorporada à Constituição de 1988 e confirmada pelo STF em 2010 - não deve impedir que se julguem os responsáveis pelos crimes.". (FOLHA DE S.PAULO, 11/12/2014);

r) "Ministros do STF divergem sobre revisão da Anistia.". (FOLHA DE S.PAULO, 11/12/2014);

s) “Comissão responsabiliza 377, e Dilma defende Lei da Anistia.". (0 GLOBO, 11/12/2014);

t) “Comissão extrapola ao pedir limitação da anistia.". (O GLOBO, 11/12/2014);

u) “Vítimas e algozes da 'guerra suja'.". (O GLOBO, 11/12/2014); 
v) "A Lei da Anistia, de 1979, vai além do perdão recíproco: ela é a expressão legal do entendimento entre militares e oposição em torno de um projeto de redemocratização sem violência.". (0 GLOBO, 11/12/2014);

w) "Comissão aponta 377 por violações; Dilma rejeita revanche". Documento final diz que violência na ditadura era parte da política de Estado e pede punição; presidente reitera defesa da Lei de Anistia e cita respeito a 'pactos políticos'.". (0 ESTADO DE S.PAULO, 11/12/2014);

$\mathrm{x}$ ) “Esse processo, cujo resultado é o relatório ora entregue pela comissão, tinha o objetivo de reescrever a história daquele período conforme uma narrativa que não só ignora os crimes da esquerda armada, como a transforma em mártir da democracia - embora agisse sob inspiração (e em alguns casos com financiamento e treinamento) de ditaduras comunistas.". (O ESTADO DE S.PAULO, 11/12/2014);

y) "Não se trata de comparar o que fizeram a guerrilha e os agentes do Estado, pois aquele era um combate obviamente assimétrico, mas não se pode ignorar que, na 'guerra suja', havia dois lados - e ambos cometeram atrocidades.". (O ESTADO DE S.PAULO, 11/12/2014);

z) "Militares repudiam relatório da comissão.". (0 ESTADO DE S.PAULO, 11/12/2014);

aa) "Comissão da Verdade conclui trabalho; tempo de violência política precisa ser conhecido e debatido, mas foi a anistia que possibilitou superá-lo.". (FOLHA DE S.PAULO, 12/12/2014);

bb) "O relatório silencia, assim, sobre os crimes das organizações armadas que combateram para substituir a ditadura militar por outra, de cunho comunista.". (FOLHA DE S.PAULO, 12/12/2014);

cc) "A anistia irrestrita, concedida pela ditadura brasileira nos seus estertores, em 1979, foi o passo decisivo para a superação pacífica dessa crônica nefanda.". (FOHA DE S.PAULO, 12/12/2014);

dd) “Relatório sobre ditadura é 'leviano' diz general.". (O ESTADo DE S.PAULO, 12/12/2014);

ee) "Após a divulgação do relatório final da Comissão da Verdade, clubes militares publicaram uma lista com 126 pessoas mortas, segundo eles, vítimas da guerrilha urbana.". (O GLOBO, 12/12/2014);

ff) "Meu pai levou 25 tiros, diz filho de vítima da esquerda.". (FOLHA DE S.PAULO, 14/12/2014);

gg) "História se faz com dois lados, diz membro da comissão.". (O ESTADO DE S.PAULO, 15/12/2014);

hh) "Brasil deve julgar os crimes dos dois lados da ditadura.". (FOLHA DE S.PAULO, 15/12/2014); 
ii) "Como já se desenhava no curso dos trabalhos da Comissão, a maioria de seus integrantes deu forma também a um preocupante equívoco, ao defender, no documento final, a revisão da Lei da Anistia.". (O GLOBO, 15/12/2014).

Foram identificadas três FDs predominantes. FD1: Revisão da Lei da Anistia, FD2: Crimes dos dois lados e FD3: Desqualificação da CNV. De acordo com Gregolim (2007, p. 15), “[...] os efeitos de sentido materializam-se nos textos que circulam em uma sociedade.". Para a autora, “[...] na sociedade contemporânea, a mídia é o principal dispositivo discursivo por meio do qual é construída uma 'história do presente' como um acontecimento que tensiona a memória e o esquecimento.”. (GREGOLIM, 2007, p. 16), sendo ela, em grande parte, que formata a historicidade que nos atravessa e nos constitui, modelando a identidade histórica que nos liga ao passado e ao presente.

Ao se observar a cobertura da imprensa, especialmente os jornais analisados, no contexto do golpe de 1964, não causa estranheza ou surpresa os sentidos que esses jornais produziram sobre a CNV. Com mais de dois anos de intervalo, entre uma cobertura e outra, as marcas principais do discurso dos jornais sobre a ditadura militar e a CNV se mantiveram. Durante o período analisado, foram publicados 24 artigos assinados. Destes, a maioria (16) defendeu a importância da criação da CNV para a consolidação democrática brasileira.

Com a cobertura realizada pelos jornais FSP, GLOBO e OESP os leitores não são contextualizados sobre o que ocorreu durante a ditadura militar brasileira de 1964 a 1985, sobre o início da luta armada ou de como configurou-se o golpe que derrubou o presidente João Goulart. Não há referências ao contexto do golpe de 1964 ou sobre o início dos movimentos de luta armada no período analisado. Entende-se que a principal razão de o golpe e seu contexto não aparecerem na cobertura está no fato de que a imprensa participou diretamente da deposição de Jango e, assim, silencia sobre um acontecimento que é definidor do cenário histórico, político, social, cultural e econômico brasileiro.

As conclusões e as 29 recomendações não mereceram a atenção dos jornais, são apenas listadas. A única que recebeu destaque foi a que se refere à Lei da Anistia. Destaca-se que é internacionalmente reconhecido o significado de uma comissão da verdade para a consolidação democrática de um país. Porém, a cobertura dos jornais analisados não reflete esse simbolismo contido na criação e efetivação da CNV.

Os sentidos que se quer evitar são apagados. Orlandi (2007) cita como exemplo de silêncio constitutivo a designação de "Nova República", no Brasil, conferida ao regime após a ditadura militar. Ao identificar-se assim esse período se estaria buscando apagar o fato de 
termos tido antes uma ditadura. Se põe em funcionamento o mecanismo: o que é preciso não dizer para poder dizer. Pode-se afirmar, "[...] generalizando, que toda denominação apaga necessariamente outros sentidos possíveis, o que mostra que o dizer e o silenciamento são inseparáveis: contradição inscrita nas próprias palavras.”. (ORLANDI, 2007, p. 74).

Para os jornais analisados, a ditadura militar brasileira foi um período de regime militar, ocorreram torturas, mortes, desaparecimentos e outras violências, mas reconhecer isso não significa que se pode aceitar "revanchismo", "acerto de contas", "punição aos agentes públicos" e muito menos revisão da Lei de Anistia. Os abusos aos direitos humanos por parte dos militares são reconhecidos, mas ficam atenuados pelo discurso dos jornais a partir dos argumentos da "guerra suja" e de que havia uma necessidade de evitar uma "ditadura comunista". A CNV é desqualificada, deslegitimada e são colocados sob suspeição sua finalidade, objetivos e resultados.

\section{Considerações}

O compromisso com a verdade factual e a pluralidade devem ser valores caros ao jornalismo. Quando se resgata a atuação da imprensa, especialmente os textos dos jornais GLOBO, OESP e FSP, no contexto do golpe de 1964, observa-se que os sentidos que esses jornais produziram sobre a CNV, durante a cobertura de seus 31 meses, mantém um padrão. Mesmo com mais de dois anos de intervalo, entre a cobertura da criação da CNV e a entrega do relatório, as marcas principais do discurso dos jornais sobre a ditadura militar e a CNV se mantiveram.

Pode-se afirmar que o cenário histórico, político, social, cultural e econômico que o Brasil enfrenta, em 2021, tem origem em seu passado mal resolvido. As consequências do golpe de 1964 e dos 21 anos de ditadura que se seguiram afetaram todos os setores da sociedade brasileira, o que acabou contaminando o presente democrático com muitas de suas práticas. Marcas do período comandado pelos militares e seus aliados estão na política, na economia, na educação, na cultura, nas forças de segurança do país. Isso precisa ser discutido. E é urgente.

Ao se analisar o contexto que envolveu a Comissão da Verdade brasileira é possível compreender um pouco sobre o que acontece hoje no país. Durante quase três décadas sob regime democrático, os defensores da política do silenciamento e do esquecimento foram mais fortes e a intenção de "virar a página" de um livro que ainda precisa ser escrito 
prevaleceu. É representativo e também simbólico para a história política do Brasil que a efetivação da CNV tenha ocorrido justamente pela ação da primeira presidente mulher do país, e que, reeleita, recebeu seu relatório final.

Neste sentido, pode-se verificar que o Brasil vinha avançando, mesmo que lentamente, na consolidação democrática, mas desde 2016, especialmente, o que se observa são retrocessos. Mais de seis anos depois do encerramento do trabalho da CNV, as Forças Armadas não atenderam a uma das 29 recomendações da $\mathrm{CNV}$, reconhecer sua responsabilidade institucional pela ocorrência de graves violações de direitos humanos durante a ditadura militar (1964 a 1985). A impunidade talvez seja a maior de todas as heranças deixadas pela ditadura militar brasileira.

Os acontecimentos dizem sobre uma sociedade. Assim, de alguma forma, os acontecimentos, vão definir uma coletividade. Aqueles acontecimentos que emergem em uma sociedade nos fornecem a sua imagem. Eles nos falam dessa sociedade naquele período, do seu conjunto de valores, do modo como vive, manifesta e cobra o cumprimento destes valores. Também os acontecimentos jornalísticos auxiliam na definição histórica de uma sociedade, já que o seu próprio processo de produção está imbuído de valores que circulam nesta mesma sociedade. 0 jornalismo profissional e sério é fundamental para a democracia.

A memória oficial e os sentidos que os militares querem dar ao período em que comandaram o país têm espaço privilegiado e garantido nos jornais. A intensa, tensa e desigual disputa pela memória e verdade histórica, que devem prevalecer sobre o que ocorreu no país, de 1964 a 1985, prossegue firme e forte, apesar do trabalho da CNV. A demanda por verdade, memória e justiça persiste. Ela continua a ser um desafio social, político e ético ao Estado brasileiro. 0 autoritarismo e o fascismo estão avançando no país e ameaçam as conquistas sociais e as instituições democráticas. Não se pode tolerar nenhum tipo de golpe que ameace a legalidade e a democracia. Para que não se esqueça. Para que nunca mais aconteça.

\section{Referências}

ABREU, Carmen. Comissão Nacional da Verdade: um acontecimento entre o passado e o futuro do Brasil. Tese (Doutorado) - Programa de Pós-Graduação em Ciências da Comunicação, Universidade do Vale do Rio dos Sinos, São Leopoldo, 2016.

AQUINO, Maria Aparecida de. Para historiadora da USP, elites brasileiras 'não evoluíram': 'ainda é muito parecido com 1964'. [Entrevista concedida a] Rafael Tatemoto. Brasil de Fato, 
São Paulo, ago. 2015. Disponível em: https://operamundi.uol.com.br/samuel/41303/parahistoriadora-da-usp-elites-brasileiras-nao-evoluiram-ainda-e-muito-parecido-com-1964>. Acesso em: 17 abr. 2019.

ARENDT, Hannah. Entre o passado e o futuro. São Paulo: Perspectiva, 2011.

BENETTI, Marcia. Análise do Discurso em Jornalismo: estudo de vozes e sentidos. In: LAGO, Cláudia; BENETTI, Márcia (org). Metodologias de pesquisa em jornalismo. Petrópolis: Vozes, 2007.

COMÍCIO da Central do Brasil. [S. l.: s. n.], [200-]. 1 vídeo (2 min). Publicado pelo canal Eduardo C. de Oliveira. Disponível em: https://www.youtube.com/watch?v=KjM48ZjevmA. Acesso em: 16 de abr. de 2019.

COMISSÃO NACIONAL DA VERDADE (Brasil). [Galeria de imagens]. 2012. Fotos: Lívia Mota.

COMISSÃO NACIONAL DA VERDADE (Brasil). Nota da CNV sobre os 50 anos do golpe de 1964. Brasília: CNV, 2014a. Disponível em: http://www.cnv.gov.br/index.php/outrosdestaques/457-nota-da-cnv-sobre-os-50-anos-do-golpe-de-estado-de-1964. Acesso em: 15 abr. 2019.

COMISSÃO NACIONAL DA VERDADE (Brasil). Relatório da Comissão Nacional da Verdade. Brasília: CNV, 2014b. 3v. Disponível em: http://cnv.memoriasreveladas.gov.br. Acesso em: 16 abr. 2019.

CORREIO BRAZILIENSE. Esposa de Jango, Maria Thereza Goulart tem vida contada em biografia. Brasília, 17 maio 2019.

DANTAS, Audálio. As duas guerras de Vlado Herzog: da perseguição nazista na Europa à morte sob tortura no Brasil. Rio de Janeiro: Civilização Brasileira, 2012.

DANTAS, Audálio. A mídia e o Golpe militar. Estudos Avançados, São Paulo, v. 28, n. 80, 2014.

O DIA que durou 21 dias. Direção: Camilo Galli Tavares. Roteiro: Camilo Galli Tavares. [S.l.]: Pequi Filmes, 2012. 1 vídeo (77 min).

O ESTADO DE S.PAULO. São Paulo: Estado de S. Paulo, 11-13 maio, 2012.

O ESTADO DE S.PAULO. São Paulo: Estado de S. Paulo, 15 maio, 2012.

O ESTADO DE S.PAULO. São Paulo: Estado de S. Paulo, 17-18 maio, 2012.

O ESTADO DE S. PAULO. Ustra nega tortura e mortes e diz que Dilma era de grupo terrorista. São Paulo, 11 maio 2013.

O ESTADO DE S.PAULO. São Paulo: Estado de S. Paulo, 8 dez. 2014.

O ESTADO DE S.PAULO. São Paulo: Estado de S. Paulo, 11-12 dez. 2014. 
O ESTADO DE S.PAULO. São Paulo: Estado de S. Paulo, 15 dez. 2014.

FERNANDES, Talita; URIBE, Gustavo. Bolsonaro determinou 'comemorações devidas' do golpe de 1964, diz porta-voz. Folha de S. Paulo, São Paulo, 25 mar. 2019.

FERREIRA, Jorge. João Goulart: uma biografia. Rio de Janeiro: Civilização Brasileira, 2011.

FERREIRA, Jorge; GOMES, Angela de Castro. 1964: o golpe que derrubou um presidente, pôs fim ao regime democrático e instituiu a ditadura no Brasil. Rio de Janeiro: Civilização Brasileira, 2014.

FICO, Carlos. 0 golpe de 64: momentos decisivos. Rio de Janeiro: Editora FGV, 2014.

FOLHA DE S. PAULO. São Paulo: UOL, 12 maio 2012.

FOLHA DE S. PAULO. São Paulo: UOL, 14 maio 2012.

FOLHA DE S. PAULO. São Paulo: UOL, 16 maio 2012.

FOLHA DE S. PAULO. Coronel enfrenta comissão e defende ação na ditatura. São Paulo, 11 maio 2013.

FOLHA DE S. PAULO. São Paulo: UOL, 7 dez. 2014.

FOLHA DE S. PAULO. São Paulo: UOL, 11-12 dez. 2014.

FOLHA DE S. PAULO. São Paulo: UOL, 14-15 dez. 2014.

FONTELES, Claudio. Tomada pública de depoimentos de agentes de repressão: Coronel Ustra. Brasília: Empresa Brasileira de Comunicação, 2013. 1 vídeo (67 min). Disponível em: https://www.youtube.com/watch?v=pWsv4EndpfY\&index=3\&list=PL9n0M0Ixl2jemD9XmE ZKzrlnqPxCra-TK. Acesso em: 16 abr. 2019.

O GLOBO. Rio de Janeiro: Grupo Globo, 15-16 maio 2012.

O GLOBO. Rio de Janeiro: Grupo Globo, 18 maio 2012.

O GLOBO. Rio de Janeiro: Grupo Globo, 11-12 dez. 2014.

O GLOBO. Rio de Janeiro: Grupo Globo, 15 dez. 2014.

GREGOLIM, Maria do Rosário. Análise do discurso e mídia: a (re)produção de identidades. Revista Comunicação, mídia e consumo, São Paulo, v. 4, n. 11, p. 11-25, nov. 2007.

MAGALHÃES, Mário. 19 capas de jornais e revistas: em 1964, a imprensa disse sim ao golpe Blog do Mário Magalhães, São Paulo, 31 mar. 2014. Disponível em: http://blogdomariomagalhaes.blogosfera.uol.com.br/2014/03/31/19-capas-de-jornais-erevistas-em-1964-a-imprensa-disse-sim-ao-golpe. Acesso em: 27 abr. 2014. 
MARCHA da família com Deus pela liberdade. 0 Estado de S. Paulo, São Paulo, p. 5, 19 mar. 1964. Disponível em: Disponível em: http://acervo.estadao.com.br/pagina/\#!/1964031927272-nac-0005-999-5-not. Acesso em: 14 abr. 2019.

MEZAROBBA, Glenda. Afinal, o que é uma comissão da verdade? Revista Direitos Humanos, Brasília, p. 32-34, 2010.

NATALINI, Gilberto. Tomada pública de depoimentos: Gilberto Natalini (ex-preso político). [Depoimento cedido à] Comissão Nacional da Verdade. Brasília: Empresa Brasileira de Comunicação, 2013. 1 vídeo (26 min). Disponível em:

https://www.youtube.com/watch?v=fqt4qQX1S48\&list=PL9n0M0Ixl2jemD9XmEZKzrlnqPxC ra-TK\&index=3. Acesso em: 16 abr. 2019.

ORLANDI, Eni. Discurso \& Leitura. São Paulo: Cortez,1988.

ORLANDI, Eni. Análise de Discurso: princípios e procedimentos. Campinas: Pontes, 1999.

ORLANDI, Eni. As Formas do Silêncio: no movimento dos sentidos. Campinas, SP: Editora da Unicamp, 2007.

PADRÓS, Henrique Serra. O resgate do passado recente e as dimensões da luta pela verdade e justiça. In: NUNES, Carmen Lúcia da Silveira; PADRÓS, Henrique Serra; LOPEZ, Vanessa Albertinence; FERNANDES, Ananda Simões. Memória, verdade e justiça: as marcas das ditaduras do Cone Sul. Porto Alegre: Assembleia Legislativa do Rio Grande do Sul, 2011.

PRESSOT, Aline. As Marchas da Família com Deus pela Liberdade: 50 anos depois. [Entrevista concedida a] Patricia Fachin. Revista IHU-Online, São Leopoldo, 19 mar. 2014.

POLLAK, Michael. Memória e identidade social. Estudos Históricos, Rio de Janeiro, V. 5, n. 10, 1992.

QUÉRÉ, Louis. Entre facto e sentido: a dualidade do acontecimento. Trajectos - Revista de Comunicação, Cultura e Educação, Lisboa, n. 6, 2005.

RELEMBRE: editorial de 0 Globo celebra golpe militar de 1964. Pragmatismo Político, [s.l.], 26 mar. 2013. Disponível em: http://www.pragmatismopolitico.com.br/2013/03/editorialglobo-celebra-golpe-militar-de-1964.html. Acesso em: 16 abr. 2019.

SABADELL, Ana Lucia; DIMOULIS, Dimitri. Anistia: A política além da justiça e da verdade. Revista Acervo, Rio de Janeiro, v. 24 n.1, p.79-102, jan./jun. 2011.

SELIGMANN-SILVA, Márcio Orlando. Tradição de 'memoricídio' se perpetua no Brasil, diz Seligmann-Silva. [Entrevista cedida a] Paula Coutinho. Jornal do Comércio, Porto Alegre, dez. 2015. Disponível:

https://www.jornaldocomercio.com/_conteudo/2015/12/politica/469953-apagamento-damemoria-se-perpetua-no-brasil-afirma-seligmann-silva.html. Acesso em: 14 abr. 2019.

SILVA, Juremir Machado da. Golpe de 1964 e o jornalismo golpista. Revista IHU On-line, São Leopoldo, 4 abr. 2014. 
SILVA, Juremir Machado da. 1964. Golpe midiático-civil-militar. Porto Alegre, RS: Sulina, 2017.

TREZZI, Humberto. Quem são e que cargos ocupam os militares no governo Bolsonaro. GZH, Porto Alegre, 10 fev. 2019.

USTRA, Carlos Alberto Brilhante. A verdade sufocada: a história que a esquerda não quer que o Brasil conheça. Brasília: Editora Ser, 2006.

USTRA, Carlos Alberto Brilhante. Tomada pública de depoimentos de agentes de repressão: Coronel Ustra. [Depoimento cedido à] Comissão Nacional da Verdade. Brasília: Empresa Brasileira de Comunicação, 2013. 1 vídeo (67 min). Disponível em:

https://www.youtube.com/watch?v=pWsv4EndpfY\&index=3\&list=PL9n0M0Ixl2jemD9XmE ZKzrlnqPxCra-TK.

\title{
The Brazilian press, the 1964 civil-military coup, and the National Truth Commission
}

\begin{abstract}
In this text, we discuss the participation of the press in the deposition of President João Goulart, a 1964 coup, and the coverage of the work of the National Truth Commission carried out by the newspapers Folha de São Paulo, O Estado de São Paulo and $\mathrm{O}$ Globo. Our objective was to highlight the main meanings that circulated, stood out, were silenced and / or erased about the Brazilian civil-military dictatorship and the National Truth Commission in the newspapers' discourse. In this coverage, the CNV is disqualified, delegitimized and co-located under suspicion its purpose, objectives and results. We believe that the historical, political, social, cultural and economic scenario that Brazil faces has its origin, mainly, in its poorly resolved past.
\end{abstract}

\section{Keywords}

1964 Coup; Military Dictatorship; National Truth Commission; Newspapers

\section{Autoria para correspondência}

Carmem Regina Abreu Gonçalves

carmenabreug@gmail.com 


\section{Como citar}

GONÇALVES, Carmen Regina Abreu; LÜBECK, Elisa. A imprensa brasileira, o golpe civil-militar de 1964 e a Comissão Nacional da Verdade. Intexto, Porto Alegre, n. 52, e-94798, 2021. DOI XXXXX.

Recebido em 24/07/2019

Aceito em 28/05/2021

(c) $(1)(9)$ 